\title{
TEKNIK BORDIR SASAK
}

\author{
Oleh: Emy Budiastuti \\ PT. Busana FT UNY
}

\section{Pendahuluan}

Membordir merupakan salah satu teknik menghias kain yang dikerjakan menggunakan mesin jahit atau mesin bordir. Namun seiring dengan perkembangan jaman, teknik membordir dapat menggunakan komputer. Menurut Heri Suhersono (2004:7), bordir sebagai salah satu kerajinan ragam hias (untuk aksesoris berbagai busana) yang menitik beratkan pada keindahan dan komposisi warna benang pada medium berbagai kain dengan alat bantu seperangkat mesin jahit (mesin jahit bordir) atau mesin jahit bordir komputer. Menurut Goet Poespa (2005:7) bordir adalah suatu elemen untuk mengubah penampilan kain dengan aneka setik bordir, baik yang dibuat dengan menggunakan tangan atau mesin. Jika setik ragam hias dibuat dengan menggunakan tangan, maka keterampilan itu disebut "sulam". Sedangkan bila dilakukan dengan menggunakan mesin maka disebut "bordir".

Pada dasarnya, membordir dengan mesin jahit dan membordir dengan mesin bordir computer hasilnya akan berbeda. Membordir dengan mesin jahit akan menghasilkan berbagai macam tusuk bordir. Sedangkan membordir dengan mesin bordir komputer, tusuk bordirnya sangat terbatas. Sehingga dalam membordir dengan mesin jahit biasa akan dapat mengembangkan berbagai jenis bordir yang hasilnya tidak kalah bagus dengan mesin bordir komputer.

Hasil membordir menggunakan mesin jahit akan terlihat halus, bagus, dan rapi jika: a) kombinasi benang dan bahan serasi; b) tusuk bordir tidak melewati garis motif; c) benda tidak berkerut atau menggelembung. Disamping itu keuletan, ketekunan, dan kesabaran merupakan modal utama dalam membordir menggunakan mesin jahit. Keseimbangan antara gerak tangan dan kaki juga akan sangat menentukan hasil akhir bordir. Terdapat dua tusuk dasar dalam membordir yaitu tusuk suji cair (seti kan biasa) dan tusuk lompat. Dengan dua tusuk dasar tersebut akan bisa dikembangkan berbagai macam jenis bordir. Terdapat beberapa macam jenis bordir, antara lain: bordir suji cair, bordir lompat pendek, bordir lompat panjang dan variasinya, bordir granit, bordir sasak, bordir aplikasi, bordir biji ketimun, bordir imitasi permadani, bordir 
benang rangkap tujuh, bordir inggris, bordir richelie dan variasinya, bordir terawang dan variasinya.

\section{Pembahasan}

Bordir sasak merupakan jenis bordir yang penyelesaiannya menggunakan tusuk lompat panjang dan lompat pendek secara tidak beraturan. Bordir sasak ini bisa untuk menghias busana maupun lenan rumah tangga.

Macam-macam bordir sasak:

1. Bordir sasak benang kombinasi

2. Bordir sasak dengan tiga warna benang (bergradasi)

3. Bordir sasak fantasi (sasak tumpuk)

4. Bordir sasak timbul (isi kapas)

5. Bordir sasak dengan batas

Dalam teknik membordir tidak bisa dipisahkan dengan disain motifnya. Dasain motif untuk bordir sasak lebih ditekankan pada jenis motif yang besar karena banyak menggunakan tusuk lompat panjang. Pada penyelesaian bordir sasak perlu diperhatikan panjang pendeknya tusuk. Biasanya panjang tusuk lompat pada bordir sasak berkisar antara 4-5 mm. Untuk menghasilkan tusuk lompat yang baik, maka pada waktu membordir posisi pengatur setikan harus dikendorkan. Jika tidak dikendorkan (seperti menjahit), maka hasilnya akan menggelembung sehingga hasil bordir tidak maksimal.

\section{Bordir sasak benang kombinasi}

Bordir sasak kombinasi adalah bordir sasak yang penyelesaiannya menggunakan benang kombinasi atau sembur (obar-abir). Bordir sasak benang kombinasi bisa untuk menghias busana (blus, gaun) maupun lenan rumah tangga (sarung bantal kursi, taplak meja, dan sebagainya). Tusuk lompat panjang yang diterapkan dalam bordir sasak ini dibuat secara tidak beraturan. Pengerjaannya dimulai dari bagian pinggir motif kemudian diarahkan ke tengah motif sampai motif penuh terisi tusuk lompat panjang. Dalam bordir sasak kombinasi ini tidak disarankan untuk membuat tusuk pipih sampai mengelilingi motif. Hal yang perlu diperhatikan dalam mengerjakan bordir sasak benang kombinasi ialah warna benang serak, artinya warna yang senada tidak berkumpul di satu bagian saja. 
Contoh bordir sasak menggunakan satu benang kombinasi (obar-abir)

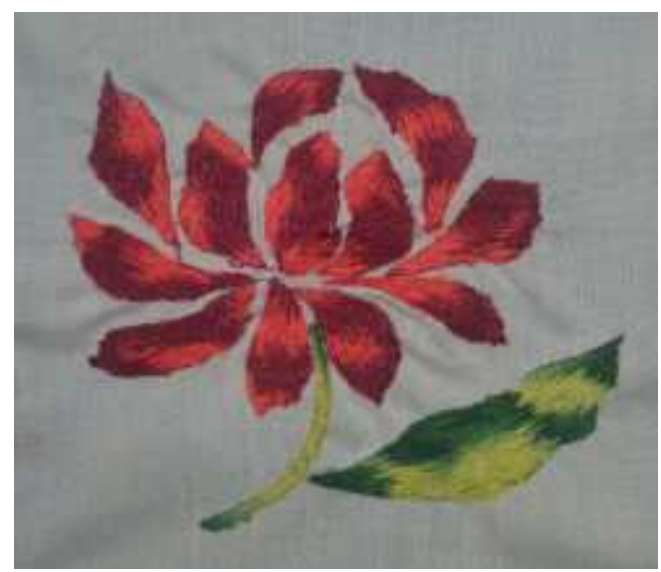

Gambar 1. Bordir sasak benang kombinasi

\section{Bordir Sasak Kombinasi dengan batas}

Bordir sasak kombinasi dengan batas sama dengan sasak benang kombinasi, tetapi pada potongan motifnya diberi antara dengan memakai benang yang warnanya lebih tua (hitam). Tujuan dengan batas disini untuk membatasi motif pada jenis motif hiasan yng bersusun. Potongan motif dibuat dengan setikan biasa (suji cair). Jadi untuk motif sasak ini dipilih motif yang bersusun, misalnya: motif bunga mawar, bunga dahlia dan sebagainya. Bordir ini baik dipakai untuk hiasan lenan rumah tangga, misal : sprei, sarung bantal dan guling, tutup TV dan lain sebagainya, dengan memilih disain motif yang besar.

\section{Bordir Sasak tiga warna benang (tiga tingkat warna benang)}

Sesuai dengan namanya, bordir sasak dengan tiga warna benang (bergradasi) merupakan jenis bordir yang menerapkan tiga warna benang dengan kombinasi yang harmonis, misal tiga macam warna benang yaitu merah muda, merah, dan merah tua. Sedangkan untuk disain motifnya, dipilih motif yang agak besar atau besar. Penggunaan tiga warna benang dapat diatur sedemikian rupa sehingga menghasilkan perpaduan warna yang baik. Antara warna benang paling muda, warna sedang dan warna tua posisinya saling menumpang. Misalnya pada bagian pinggir motif menggunakan warna benang muda, kemudian warna sedang .dan yang paling dalam menggunakan warna benang tua. Hal penting yang harus diperhatikan dalam membordir sasak tiga warna yaitu antara warna benang satu dengan yang lain tidak berimpitan tetapi menumpang sedikit (Emy Budiastuti, 1990:20-23)

Contoh bordir sasak tiga warna benang (bergradasi) 

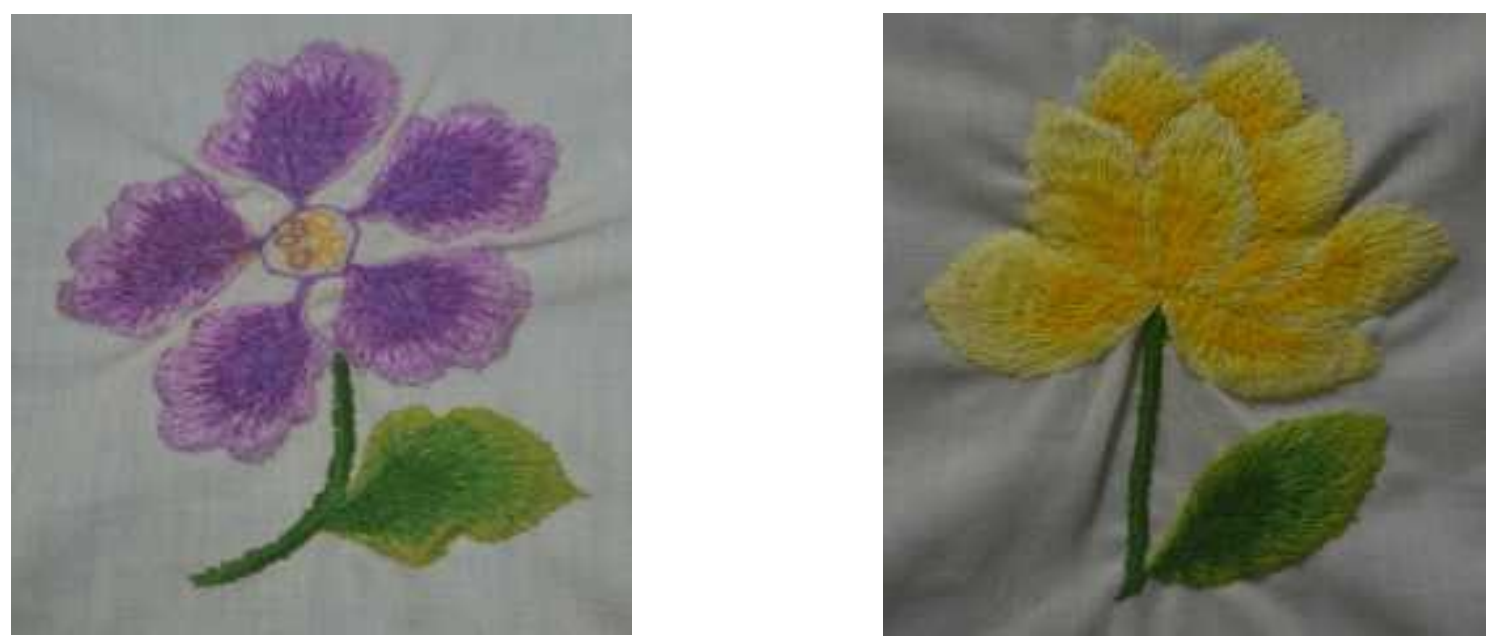

Gambar 2 dan 3. Bordir Sasak Tiga Warna Benang
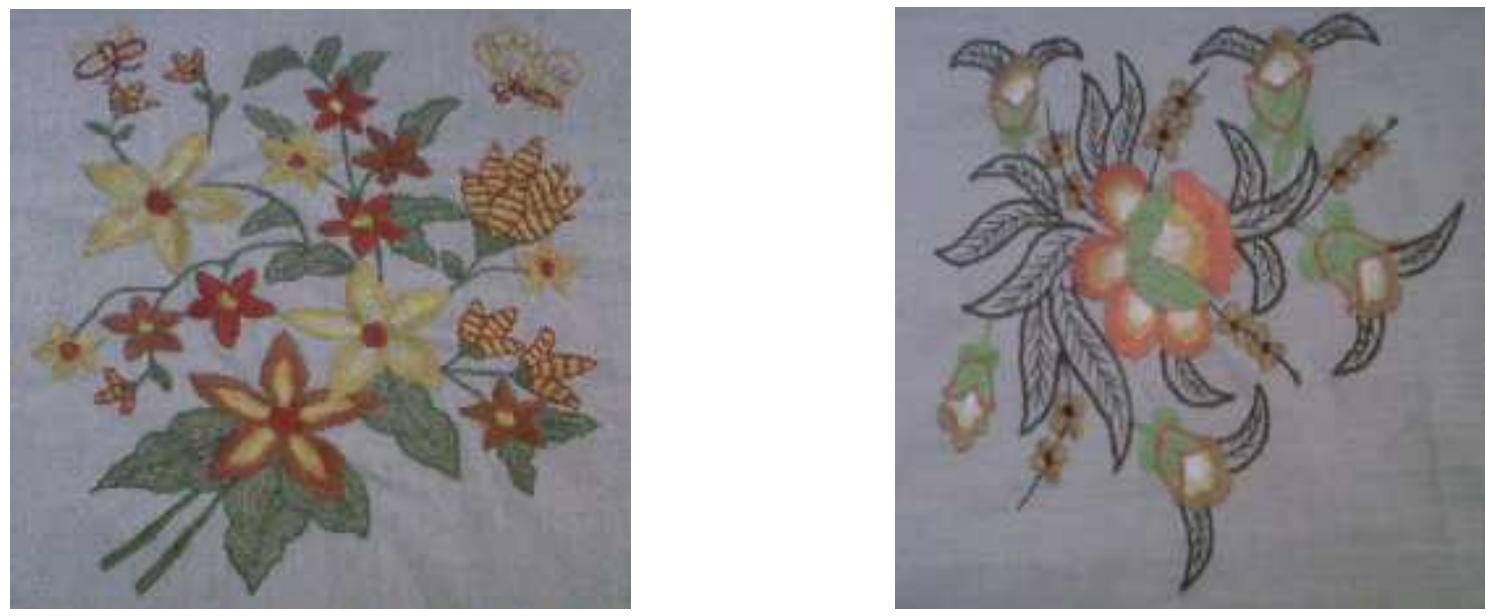

Gambar 4 dan 5. Kombinasi bordir sasak tiga warna benang dengan tusuk bordir lain

\section{Bordir Sasak Fantasi (Bordir Sasak Tumpuk)}

Bordir fantasi ini identik dengan bordir sasak kombinasi, hanya saja motifnya dibuat 3-4 kali dengan ukuran berbeda. Oleh karena itu sebelum membordir, perlu mendisain motif yang sama bentuknya sebanyak 3-4 kali hanya saja ukurannya berbeda. Misalnya disain motif bunga, maka gambar bunga besarnya bertingkat dari kecil kemudian besar. Bordir fantasi (bordir sasak tumpuk) sangat cocok digunakan untuk hiasan dinding. Cara mengerjakan bordir fantasi motif bunga, yaitu:

1. Menyiapkan disain motif 
2. Mengutip motif pada bahan. Disain motif yang dikutip pada bahan yang akan dihias (bahan dasar) adalah disain yang ukurannya paling besar lengkap dengan daunnya. Disain motif dengan ukuran yang lebih kecil dikutip pada bahan lain

3. Garis motif dikerjakan dengan suji cair (setikan biasa)

4. Motif pada bahan dasar diselesaikan dengan tusuk lompat panjang, dimulai dari pinggir menggunakan warna paling muda, kemudian sedang dan paling akhir menggunakan benang warna tua.

5. Motif pada bahan lain dikerjakan sama, namun pada bagian motif paling luar ditumpangi dengan tusuk lompat pendek kemudian digunting

6. Setelah masing-masing motif dibordir kemudian ditumpuk, dilekatkan dengan suji cair yang dibentuk menyerupai benang sari

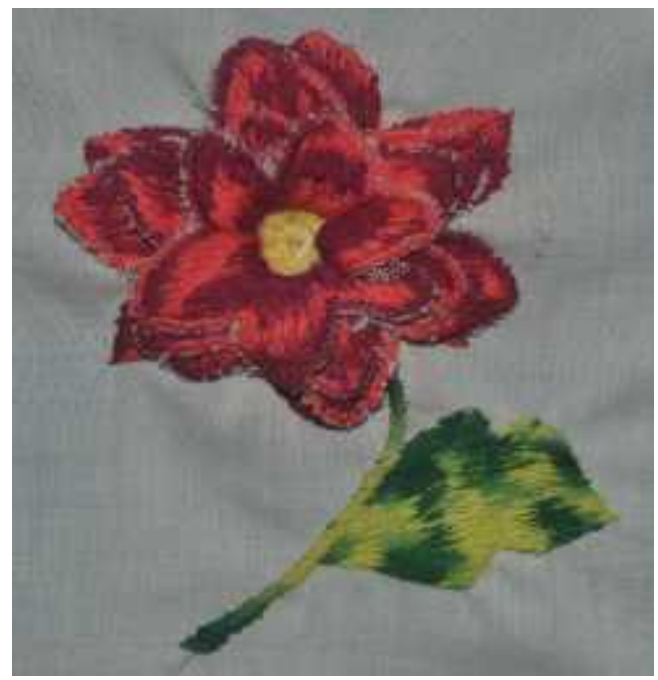

Gambar 6. Bordir Sasak Fantasi

\section{Bordir Sasak Timbul (Bordir Sasak Isi Kapas)}

Bordir Sasak Timbul atau Bordir Sasak Isi Kapas dalam menghias kain biasa disebut matelase atau sulaman relief. Bordir sasak timbul adalah bordir sasak yang diisi kapas, sehingga bentuknya timbul. Motif dipilih yang tidak terlalu lebar agar mendapatkan hasil yang bagus. Bordir sasak timbul sangat cocok untuk menghias benda berupa hiasan dinding, tutup teko, dollees dan sebagainya. Pemilihan benang bisa menggunakan tiga warna benang. Cara mengerjakan bordir timbul sama dengan bordir tiga warna, hanya saja motif dikerjakan pada bahan lain, setelah selesai digunting. Motif sasak yang digunting ditempelkan pada bahan dasar 
yang akan dihias tepat pada gambar motif, menggunakan tusuk suji cair, kemudian diisi dengan kapas. Selanjutnya menutup motif yang telah terisi kapas dengan tusuk lompat panjang.

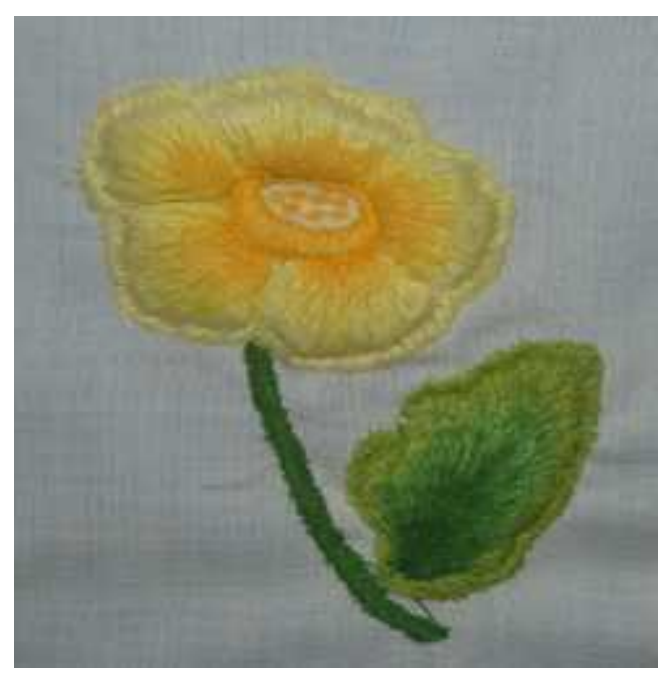

Gambar 7. Bordir Sasak Timbul (Bordir sasak isi kapas)

\section{Penutup}

Membordir menggunakan mesin jahit biasa maupun mesin jahit komputer, merupakan kegiatan keterampilan yang mudah dikerjakan. Ketekunan, keuletan, telaten merupakan modal dasar belajar membordir disamping keseimbangan antara gerak tangan dan kaki, sehingga akan dengan mudah mengembangkan macam-macam jenis bordir. Salah satu jenis bordir yang mudah dalam mengerjakannya adalah bordir sasak. Satu hal yang perlu diperhatikan sebelum membordir sasak adalah posisi pengatur setikan mesin harus dikendorkan agar hasil akhir bordir sasak rapi dan tidak berkerut.

\section{Daftar Pustaka}

Emy Budiastuti. 1990. Teknik membordir. Yogyakarta: FPTK IKIP Yogyakarta

Goet Poespa. 2005. Panduan membuat ragam hias motif bordir serta penerapannya. Jakarta: PT. Gramedia Pustaka Utama

Hery Suhersono. 2004. Desain bordir motifflors dsn dekorstif. Jakarta: PT Gramedia Pustaka Utama 
